\title{
Penetration of paclitaxel and 5-fluorouracil in multicellular layers of human colorectal cancer cells
}

\author{
MI-SUN CHOI*, SOO-HYUN KIM* ${ }^{*}$ and HYO-JEONG KUH \\ Department of Biomedical Sciences, College of Medicine, The Catholic University of Korea, Seoul, Republic of Korea
}

Received October 1, 2010; Accepted November 26, 2010

DOI: $10.3892 /$ or.2011.1138

\begin{abstract}
Limited efficacy of chemotherapeutic drugs against solid tumors has been attributed to poor drug penetration into tumor tissues. Multicellular layer (MCL) cultures recapitulate barriers to drug penetration and distribution and have been used successfully in the production of clinically relevant data. In the present study, we evaluated the characteristics of paclitaxel (PTX) and 5-fluorouracil (5-FU) penetration and their effects on tissue penetration using MCLs of human colorectal cancer cells (DLD-1 and HT-29) grown in Transwell inserts. Drug concentration in conditioned media after MCL penetration was estimated using \% survival of cells exposed to the conditioned media, and the penetration rate was calculated as \% drug concentration relative to the expected concentration after penetration of cell-free MCLs. PTX showed limited penetration in both MCLs in contrast to the full penetration seen by 5 -FU. The penetration rate measured after $24 \mathrm{~h}$ by cytotoxicity of the conditioned media was 40 and $38 \%$ in DLD-1 $(20 \mu \mathrm{M})$ and HT-29 MCLs $(1 \mu \mathrm{M})$, respectively, at which concentration the conditioned media produced $50 \%$ growth inhibition in monolayers. The penetration profile obtained using $\left[{ }^{14} \mathrm{C}\right]$-paclitaxel also showed slow and limited penetration with concentration- and cell line-dependency. In HT-29 MCL, full penetration of PTX was obtained at $10 \mu \mathrm{M}$ after $48 \mathrm{~h}$, whereas only $80 \%$ was obtained at $1 \mu \mathrm{M}$. In DLD-1 MCLs, penetration of PTX was minimal, especially at $1 \mu \mathrm{M}$, showing penetration rates as low as 10 and $20 \%$ after 24 and $96 \mathrm{~h}$, respectively. When PTX and 5-FU were allowed to penetrate in sequential combination, no effect on the penetration rate was observed. Overall, our results demonstrated limited penetration of PTX in human colorectal cancer MCLs along with concentration-, time-, and cell line-dependency. Assessment of penetration
\end{abstract}

Correspondence to: Dr Hyo-Jeong Kuh, College of Medicine, The Catholic University of Korea, 505 Banpo-dong, Seocho-ku, Seoul 137-701, Republic of Korea

E-mail: hkuh@catholic.ac.kr

*Contributed equally

Key words: paclitaxel, 5-fluorouracil, multicellular layer, drug penetration, drug combination using cytotoxicity of the conditioned media used in the present study may be useful in early stage screening of anticancer agents for their potential in tissue penetration.

\section{Introduction}

Limited efficacy of chemotherapeutic agents in various solid cancers has been attributed to drug resistance of human solid tumors. Resistance mechanisms have mainly been investigated using a monolayer culture system, focusing on factors related to molecular biological changes in induction of apoptosis and modulation of protein expression (including topoisomerases and DNA repair enzymes) (1). An association between resistance mechanisms relevant to clinical resistance and the microenvironment of solid tumors has recently been demonstrated $(2,3)$. The microenvironment of solid tumors consists of three-dimensional structure of cancer cells as well as abnormal vasculature induced by angiogenesis, hypoxicregions, abundance of extracellular matrix, immune cells, and fibroblasts. Multicellular resistance (MCR) induced by cellular contact in three-dimensional structures has been suggested as a primary mechanism of chemo-resistance (1). In addition, poor drug penetration into tumor tissue due to poor vasculature and increased interstitial pressure is considered to be an important factor limiting chemotherapeutic efficacy $(4,5)$. For example, doxorubicin (DOX) and paclitaxel (PTX) showed limited distribution around blood vessels in a mouse mammary tumor model in vivo (6), or to peripheral regions in histocultures of human pharynx xenograft (7). Innovative strategies using tumor-penetrating peptides for enhancement of drug distribution have been reported $(8,9)$ and such research efforts are expected to increase in order to improve clinical efficacy of chemotherapeutic drugs against human solid tumors.

Three dimensional (3-D) in vitro models of human solid tumors maintain tumor conditions in vivo $(4,10,11)$. These conditions include 3-D architecture, abundance of ECM, cell-cell, and cell-ECM interactions, which are known to be major contributors to MCR of human solid tumors. In contrast to low clinical relevance of conventional monolayer cultures, 3-D models, such as multicellular spheroids (MCS) and multicellular layers (MCL), represent clinically relevant in vitro models for the study of pharmacokinetics and pharmacodynamics of anti-cancer drugs $(2,3)$. In particular, MCLs have been successfully used in the study of pharmacokineticpharmacodynamic (PK-PD) relationships of chemocherapeutic agents (12-16). 
5-Fluorouracil (5-FU) has been used as the representative chemotherapeutic agent for advanced colorectal cancers. 5-FU is also used in combination with leucovorin and oxaliplatin (FOLFOX), or along with radiation therapy. PTX is one of the most important anti-cancer drugs developed in the past two decades and its efficacy has been confirmed for treatment of gastric as well as breast and ovarian cancers (17). In addition, PTX has recently been studied as a tumor priming agent to increase penetration of drugs and/or nanomedicines into tumor tissue (18). The tumor priming effect of PTX was attributed to expansion of interstitial space caused by reduced epithelial cell density following apoptotic cell killing (18).

In the present study, we investigated drug penetration of PTX and 5-FU and their interaction in terms of tissue penetration in multicellular layers (MCLs) of human colorectal cancer cells (DLD-1 and HT-29). Penetration of each drug was evaluated using activity-guided assays in which \% penetration was calculated directly from the remaining activity of conditioned media after drug passage through cell layers. Using radiolabelled compounds, we also examined concentration- and cell line-dependent penetration kinetics of these agents. PTX showed limited penetration in both MCLs; however, 5-FU showed no barrier. Additional penetration enhancing effect was not observed for either drug when given in sequential combination.

\section{Materials and methods}

Cell culture. Human colon cancer cell lines (DLD-1, HT-29) were purchased from the Korean Cell Line Bank (Seoul, South Korea) and maintained in RPMI-1640 (Gibco BRL, Grand Island, NY) supplemented with 10\% FBS (Welgene Inc., Daegu, South Korea), $100 \mathrm{U} / \mathrm{ml}$ penicillin, and $100 \mu \mathrm{g} / \mathrm{ml}$ streptomycin (Sigma Chemical Co., St. Louis, MO) in a humidified $5 \% \mathrm{CO}_{2}$ atmosphere at $37^{\circ} \mathrm{C}$.

Reagents. Paclitaxel (PTX) was donated by Hanmi Research Center Co., Ltd. (Giheung, South Korea). 5-Fluorouracil (5-FU) was purchased from Sigma Chemical Co. $\left[{ }^{14} \mathrm{C}\right]-\mathrm{Mannitol}$ (specific activity: $53 \mathrm{mCi} / \mathrm{mmol}$ ) and $\left[{ }^{14} \mathrm{C}\right]-\mathrm{PTX}$ (specific activity: $73 \mathrm{mCi} / \mathrm{mmol}$ ) were purchased from Moravek (Brea, CA, USA). Sulfordamine B (SRB), tricholoroacetic acid (TAC), glacial acetic acid, and other reagents were purchased from Sigma Chemical Co.

Culture of MCL. Cells were grown on collagen-coated microporous $(0.4 \mu \mathrm{m})$ membranes in Transwell inserts (Corning Costar, Acton) at a plating density of $3 \times 10^{5}$ cells $/ 200 \mu \mathrm{l}$ for DLD-1 and HT-29 cell lines. Six inserts were placed in a culture jar [82x57x48 mm (WxLxH), Fig. 1A] supplemented with $150 \mathrm{ml}$ RPMI-1640 media with continuous stirring in the bottom chamber. Cells were then incubated at $37^{\circ} \mathrm{C}$ in an atmosphere containing $5 \% \mathrm{CO}_{2}$ for up to 5 to 7 days. For haematoxylin and eosin staining $(\mathrm{H} \& \mathrm{E})$, cultured transwells were fixed in $4 \%$ paraformaldehyde solution for $24 \mathrm{~h}$, dehydrated through a graded series of ethanol, and embedded in paraffin. Sections $(5 \mu \mathrm{m})$ were cut and stained for morphological examination.

Post-penetration activity of PTX and 5-FU through MCL. For drug penetration study, transwells were transferred to 6-well plates and a plastic adaptor was used to keep the top chamber $(200 \mu \mathrm{l})$ from immersion into the bottom chamber ( $7 \mathrm{ml})$. Media containing paclitaxel $(200 \mu \mathrm{l})$ or 5 -FU was applied to the top chamber and incubated under cell culture conditions. Using the SRB assay, cytotoxicity in the conditioned media of the bottom chamber was assessed after 24-h penetration through MCL. For sequential combination treatment, each drug was given for $24 \mathrm{~h}$ and the top chamber was washed using PBS before loading the second drug. Reference values were obtained with culture media containing each drug at the diluted concentration, with consideration for top and bottom chamber volumes. Reference values represent drug activity with $100 \%$ penetration through MCL. Monolayer cells were exposed to drug-containing media for $72 \mathrm{~h}$ under cell culture conditions. Following drug exposure, cells were then fixed with $10 \%$ TCA and stained with $0.4 \%$ SRB for $10 \mathrm{~min}$. Protein-bound dye was extracted with $10 \mathrm{mM}$ buffered Tris, and the optical absorbance of each well was measured at $565 \mathrm{~nm}$. Data are expressed as mean $\pm \operatorname{SD}(n=3)$.

Penetration profile of $\left[{ }^{14} \mathrm{C}\right]$-mannitol and $\left[{ }^{14} \mathrm{C}\right]-\mathrm{PTX}$. MCL transwells were transferred to 6-well plates and kept floating using a plastic adapter, as described above. Media (100 $\mu \mathrm{l})$ containing $8 \mu \mathrm{M}\left[{ }^{14} \mathrm{C}\right]$-mannitol and 1 or $10 \mu \mathrm{M}$ of $\left[{ }^{14} \mathrm{C}\right]-$ PTX was applied to the top chamber of the MCL. Transwells were incubated under cell culture conditions until $96 \mathrm{~h}$, and the appearance of radioactivity as a function of time was then assessed by liquid scintillation counting of $100 \mu \mathrm{l}$ samples withdrawn from the bottom chamber.

Data analysis. Changes in cell growth (\% cell survival) were calculated using Eq. i). The median effect model was used for analysis of cell survival data Eq. ii).

$\%$ Cell Survival $=\left(\frac{\text { mean absorbance of treated cells }}{\text { mean absorbance of control cells }}\right) \times 100$ i)

$\%$ Cell Survival $=(100-R) \times\left(1-\frac{\left[D^{\mathrm{m}}\right]}{\mathrm{K}_{\mathrm{d}}^{\mathrm{m}}+\left[D^{\mathrm{m}}\right]}\right)+R$

Where [D] is the drug concentration, $K_{d}$ is the concentration of drug that produces a $50 \%$ reduction in the maximum inhibition rate (Emax), $\mathrm{m}$ is a Hilltype coefficient, and $R$ is the residual unaffected (resistance) fraction ( $R=100$ - Emax). $\mathrm{IC}_{50}$ was defined as the drug concentration required to reduce viability to $50 \%$ of the control (i.e., $\mathrm{K}_{\mathrm{d}}=\mathrm{IC}_{50}$ when $R=0$ ). Paired t-test (Figs. 3 and 5) and ANOVA followed by Tukey HSD (Fig. 5) were used to test the statistical significance of the data. Statistical analyses were performed using SPSS for Windows, version 13.0.0. $\mathrm{P}<0.05$ were considered statistically significant.

\section{Results}

Morphological characteristics of MCL of DLD-1 and HT-29 cells. DLD-1 and HT-29 cells were cultured on transwell inserts to form MCL (Fig. 1A). After 5 days of culture, MCL showed a thickness of $71.3 \mu \mathrm{m}$ (8 cell layers) and $62.5 \mu \mathrm{m}$ 
(A)

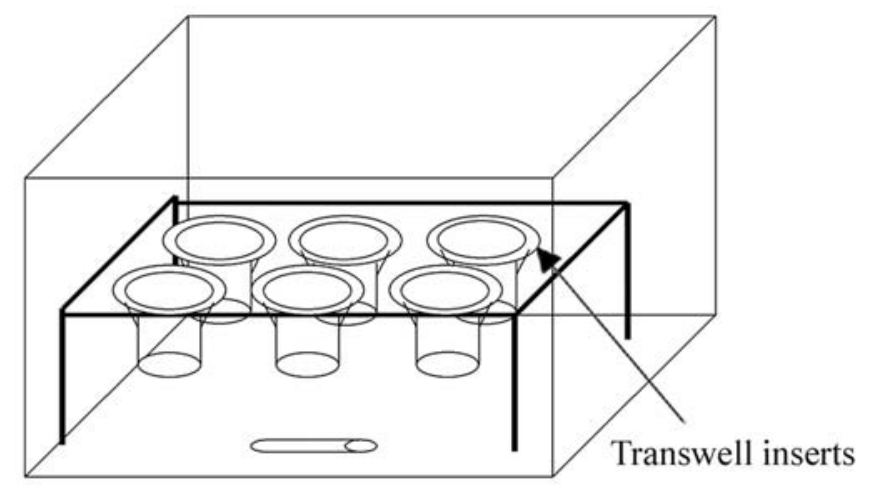

(B)

(C)
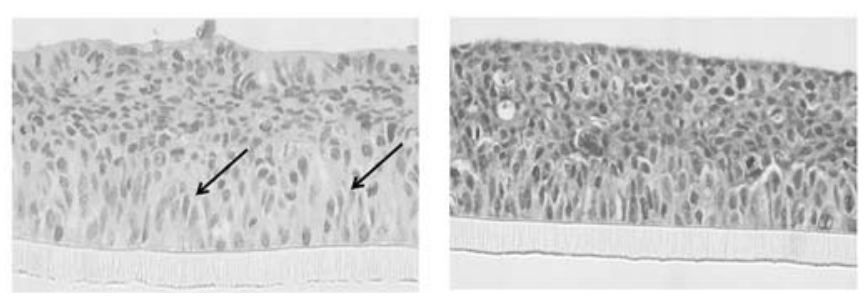

Figure 1. MCL cultures for drug penetration study. Culture device used to grow MCLs (A). Representative H\&E histological cross section of MCL's of DLD-1 (B) and HT-29 (C) cells after 5 days of culture. Acinar-like structure is indicated by arrow in (B).

(9 cell layers) on H\&E stained sections of paraffin blocks for DLD-1 and HT-29 cells, respectively (Fig. 1B and C). Structures were compact and no regions of necrosis were found. Different patterns of cell aggregation were observed between regions near and far from the membrane: cells near the membrane showed larger cytoplasm compared to cells near top layers. In DLD-1 MCL, some cells near the membrane showed an organization similar to that found in the structure of acinar cells (Fig. 1B). The highest cell density was seen in the middle region of both MCLs, appearing as a squamous band-like structure.

Anti-proliferative activity of PTX and 5-FU in monolayers. Anti-proliferative effects of PTX and 5-FU were examined in DLD-1 and HT-29 monolayers and shown as a dose-response (D/R) curve (Fig. 2). IC $_{50}$ of PTX was $133 \mathrm{nM}$ and $4.67 \mathrm{nM}$ in DLD-1 and HT-29 cells, respectively, showing a 28-fold difference. HT-29 cells showed a significantly greater sensitivity to PTX, with a very steep slope, compared to DLD- 1 cells. On the other hand, $\mathrm{IC}_{50}$ of 5-FU was $2.95 \mu \mathrm{M}$ and 4.28 $\mu \mathrm{M}$ in DLD-1 and HT-29 cells, respectively, showing similar activity.

Post-penetration activity of PTX and 5-FU through MCL. To examine penetration of PTX and 5-FU through MCL, we measured the anti-proliferative activity of the conditioned media, in which drugs were allowed to diffuse into and across MCL for $24 \mathrm{~h}$ (Fig. 3). Drug was applied to the top chamber and incubated for $24 \mathrm{~h}$ to obtain the conditioned media in the bottom chamber. Reference values were obtained for each concentration using an estimated dilution rate (35-fold) and represented cytotoxicity of the drug when penetrated $100 \%$ through MCL. In order to exclude the possibility of nonspecific binding to culture plastics, the anti-proliferative activity of the reference group was compared to media incubated in transwell inserts without cells (Fig. 3A). Neither drug showed non-specific binding to culture plastics during the penetration period, as demonstrated by $\%$ survival of conditioned media of the cell free insert equivalent (or even decreased) to the diluted one (reference value) (Fig. 3A).

Anti-proliferative activity of PTX after MCL penetration was evaluated in the loading concentration range of $2-20 \mu \mathrm{M}$

\section{(A)}



(B)

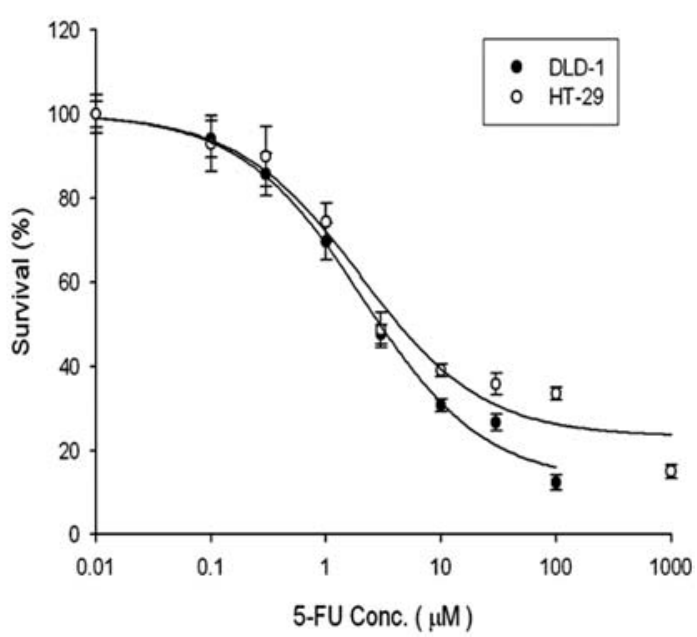

Figure 2. Dose-response curve of PTX (A) and 5-FU (B) in DLD-1 (•) and HT-29 (॰) cells grown as monolayers. Cells were exposed to drugs for 72 h and cell viability was determined using an SRB assay. Data are expressed as the mean \pm SD $(n=3)$. 
(A)



(B)

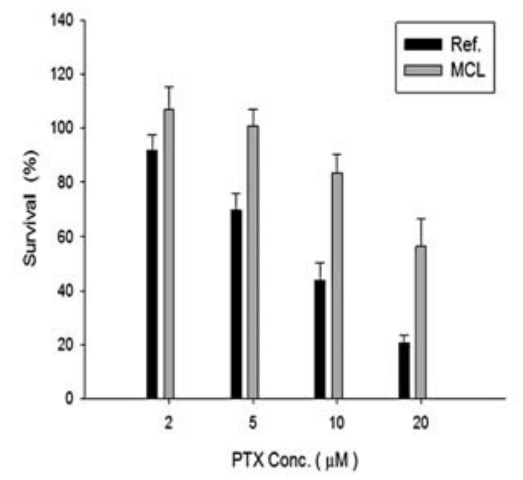

(D)



(C)

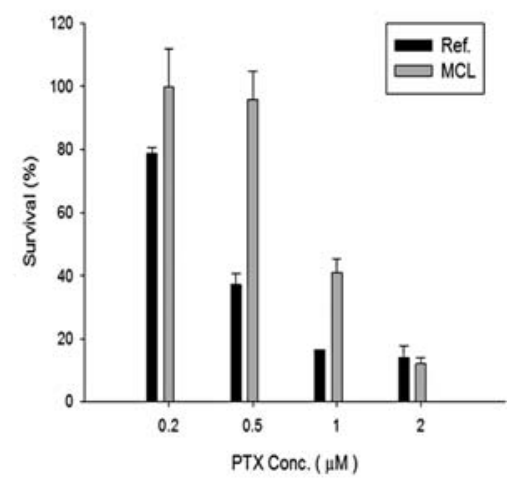

(E)



Figure 3. Anti-proliferative activity of PTX and 5-FU after penetration through MCLs. Activity was determined using conditioned media of DLD-1 (B and D) and HT-29 (C and E) MCL incubated with PTX (B and C) or 5-FU (D and E). Drugs were applied to the top chamber and the conditioned media of the bottom chamber were collected after $24 \mathrm{~h}$. References were prepared according to the estimated dilution rate (35-fold), which represents $100 \%$ penetration of drug through MCL. Anti-proliferative activity of reference media was compared to conditioned media obtained from cell-free inserts (A) in order to examine non-specific binding of drugs to MCL culture plastics. Data are expressed as the mean \pm SD ( $n=3$ ).

and $0.2-2 \mu \mathrm{M}$ in DLD-1 and HT-29 MCLs, respectively (Fig. 3B and C). In DLD-1 MCL, \% survival increased after MCL penetration in the whole range of loading concentration (Fig. 3B). Anti-proliferative activity was not observed up to $5 \mu \mathrm{M}$ (\% survival approaching 100\%) after penetration. The
\% survival for PTX conditioned media of HT-29 MCL also showed a dramatic increase over the range of PTX loading concentration up to $1 \mu \mathrm{M}$ (Fig. 3C). Note that changes in $\%$ survival were small or minimal at concentrations as high as $2 \mu \mathrm{M}$ of PTX in HT-29 (Fig. 3C). The reason for this was 
(A)

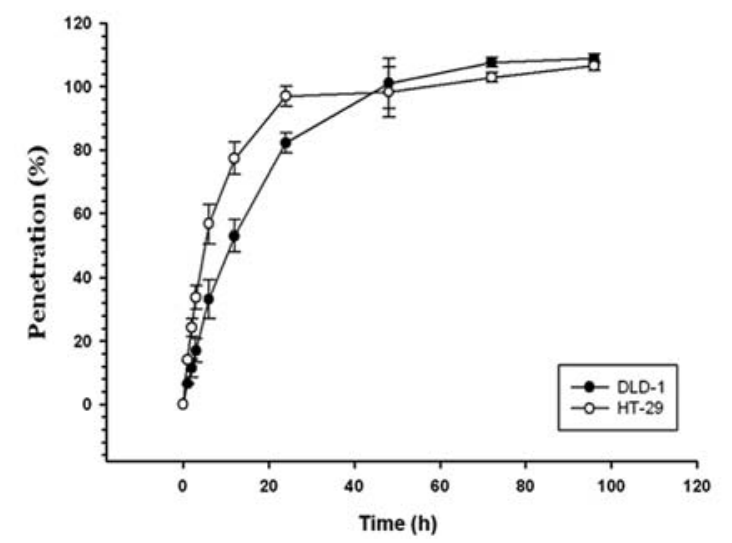

(B)

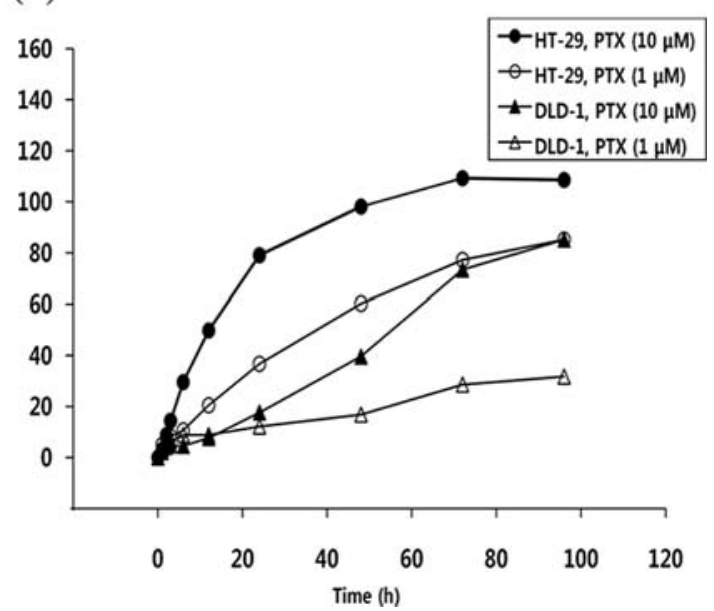

Figure 4. Penetration profile of $\left[{ }^{14} \mathrm{C}\right]$-mannitol $(0.2 \mu \mathrm{Ci})(\mathrm{A})$ and $\left[{ }^{14} \mathrm{C}\right]-\mathrm{PTX}(\mathrm{B})$. Penetration profiles were compared between MCLs of HT-29 and DLD-1 cells. Data are expressed as the mean \pm SD $(n=3)$.

that due to the sigmoidal shape of the dose-response curve, $\%$ survival $>90 \%$ or $<10 \%$ did not correlate with the actual amount of drug in the media. Hence, drug concentrations were estimated only when $\%$ survival of both reference and conditioned media was in the range of $20-80 \%$, i.e., 10 and $20 \mu \mathrm{M}$ for DLD-1 and 0.5 and $1 \mu \mathrm{M}$ for HT-29.

Penetration rate of PTX in DLD-1 MCL calculated at 10 and $20 \mu \mathrm{M}$ loading concentration was 34.9 and $40.4 \%$, respectively (Fig. 3B). In HT-29, \% penetration of PTX was calculated at 0.5 and $1 \mu \mathrm{M}$ loading concentration and was 24 and $37.7 \%$, respectively (Fig. 3C). Both cell lines showed similar \% penetration of $40.4 \%$ (DLD-1) and $37.7 \%$ (HT-29) at the higher concentration tested, 20 and $1 \mu \mathrm{M}$, respectively. Despite a 20 -fold difference in loading concentrations, they can be regarded as pharmacodynamically equivalent since the conditioned media produced $50 \%$ cell survival in monolyers of each cell line. In HT-29 cells, penetration rate appeared to be concentration-dependent, i.e., $24 \%$ at $0.5 \mu \mathrm{M}$ vs. $37.7 \%$ at $1 \mu \mathrm{M}$ (Fig. 3C); however, the concentration dependency could not be determined beyond $1 \mu \mathrm{M}$ due to limitation of the bio-assay. These data indicate that rate of tissue penetration may be drug-dependent as well as concentration-dependent. Due to a 28-fold difference in sensitivity to PTX, penetration rate between DLD-1 and HT-29 MCL could not be properly compared using the bio-assay described above. Hence, comparison of PTX penetration between the two MCLs was made using radio-labelled PTX (Fig. 4).

For the post-penetration activity of 5-FU, no increase in $\%$ survival was observed, indicating that full penetration of 5-FU occurred through DLD-1 and HT-29 MCLs or that a limited penetration was compensated by metabolic activation while moving through the cell layers (Fig. 3D and E).

Penetration of $\left[{ }^{14} \mathrm{C}\right]$-mannitol and $\left[{ }^{14} \mathrm{C}\right]-\mathrm{PTX}$. Using ${ }^{14} \mathrm{C}$ labelled compounds, the time-profile for penetration of PTX was evaluated and compared with mannitol (Fig. 4). As expected for mannitol, a representative agent for passage via a paracellular pathway, its penetration was rapid, so that $>50 \%$ penetration was observed within $12 \mathrm{~h}$ in both MCLs (Fig. 4A). Although full penetration was obtained within $48 \mathrm{~h}$ in both MCLs, penetration of mannitol was faster in HT-29 compared to DLD-1, as indicated by $\mathrm{t}_{1 / 2}$ of 5.13 and $11.1 \mathrm{~h}$, and by the time required to reach maximum (plateau) penetration of 24 and $48 \mathrm{~h}$ in HT-29 and DLD-1, respectively.

Compared to mannitol, penetration of PTX was slower and the rate and extent of penetration was dependent on the drug concentration (Fig. 4B). In HT-29 MCL, $10 \mu \mathrm{M}$ of PTX showed full penetration after $48 \mathrm{~h}$, whereas $1 \mu \mathrm{M}$ of PTX showed only $85 \%$ penetration until $96 \mathrm{~h}$. In DLD-1 MCL, the penetration of PTX was minimal, particularly at $1 \mu \mathrm{M}$, showing penetration rates as low as $10 \%$ and $20 \%$ after 24 and $96 \mathrm{~h}$, respectively. After $96 \mathrm{~h}$, DLD-1 showed $85 \%$ penetration at $10 \mu \mathrm{M}$ and $32 \%$ penetration at $1 \mu \mathrm{M}$. Concentration dependency was greater in DLD-1 MCL, where changes in the slope of the penetration curve were observed after an initial 'lag-time' period. In DLD-1 MCL, penetration showed a gradual increased with time; nonetheless, full penetration was not observed until $96 \mathrm{~h}$. In addition to concentrationdependency, cell line-dependency was also observed, i.e., PTX showed greater penetration in HT-29 compared to DLD-1. At a lower concentration of $1 \mu \mathrm{M}$, HT-29 showed 2.7-fold greater penetration of PTX than DLD-1, as measured at $96 \mathrm{~h}$, although the difference was smaller at higher concentrations of $10 \mu \mathrm{M}$ PTX.

Effect of drug combination on penetration through MCL. In order to evaluate the effect of combination in drug penetration, MCLs were sequentially exposed to the combination of PTX and 5-FU, and the anti-proliferative activity of the conditioned media was compared with that of each single drug exposure (Fig. 5). Sum of treatment represents the antiproliferative activity of combined conditioned media obtained from separate MCLs exposed to each drug for $24 \mathrm{~h}$. In DLD-1 MCL, \% survival of a single drug exposure (PTX $10 \mu \mathrm{M}$ or 5-FU $100 \mu \mathrm{M}$ ) was $83.4 \%$ and 73.2\%, respectively (Fig. 5A). When two drugs were combined, $\%$ survival decreased by $10-20 \%$, regardless of the mode of combination $(\mathrm{P}<0.05)$, i.e., $\%$ survival was $62,54.3$, and $52 \%$ for the sum of single treatment groups, PTX followed by 5-FU, and 5-FU followed by PTX, respectively. Sequential treatment produced lower $\%$ 
(A)

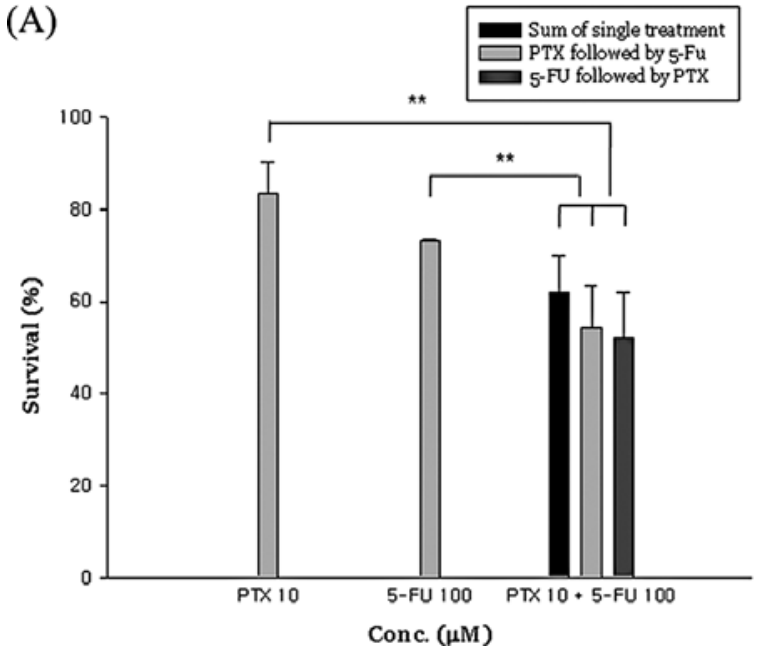



Figure 5. Anti-proliferative activity of PTX and/or 5-FU in conditioned media obtained after penetration alone or in combination through the MCLs of DLD-1 (A) and HT-29 (B) cell lines. Sequential treatment of PTX followed by 5-FU or 5-FU followed by PTX was evaluated. Statistical significance was obtained between single treatment and each of the combination groups (paired t-test, ${ }^{* *} \mathrm{P}<0.05$ ), but not among combination groups, as indicated. Data are expressed as the mean $\pm \operatorname{SD}(n=3)$

survival compared to that of a simple mixture (52\% vs. $62 \%)$; however, the difference was not statistically significant. In HT-29 MCL, \% survival of each drug exposure (PTX $0.5 \mu \mathrm{M}$ or 5 -FU $100 \mu \mathrm{M}$ ) was $95.7 \%$ and $76.9 \%$, respectively (Fig. 5B). When two drugs were combined, \% survival decreased, compared to PTX $0.5 \mu \mathrm{M}$, regardless of the mode of combination $(\mathrm{P}<0.05)$, but similar to that of 5 -FU $100 \mu \mathrm{M}$. There was no statistical significance among the three modes of combinations. These data indicate that PTX and 5-FU did not produce any significant effect on the penetration of each through MCLs of DLD-1 and HT-29 cells.

\section{Discussion}

Limited efficacy of chemotherapeutic drugs against solid tumors has been attributed to poor drug penetration into tumor tissue $(2,3)$. A nanoformulation of irinotecan, PTX-loaded microsparticle (TPM), and tumor-penetrating peptide (iRGD) have been reported to enhance distribution of various anticancer drugs, including small compounds, liposomal drugs, and monoclonal antibodies into tumor tissue in vivo $(9,18,19)$. In the present study, we evaluated the penetration characteristics of PTX and 5-FU using MCL of human colorectal cancer cells (DLD-1 and HT-29) grown in Transwell inserts. We also intended to use this MCL model for analysis of drugdrug interaction in respect to drug distribution into multicell layers in vitro. Data obtained from this model can provide clues as to whether or not pharmacokinetic interaction exists among anticancer drugs given in combination, and can suggest appropriate drug combinations for enhancement of drug distribution into tumor tissue that should entail increased efficacy.

To examine penetration of PTX and 5-FU through MCL, we measured the anti-proliferative activity in the conditioned media following penetration (Fig. 3). The \% survival of cells exposed to the conditioned media was determined in order to estimate the drug concentration in the conditioned media based on $\mathrm{D} / \mathrm{R}$ curves obtained for each drug (Fig. 2). The reference value of $\%$ survival was obtained after 35 -fold dilution assuming $100 \%$ penetration, i.e., drug molecules diffused from $200 \mu \mathrm{l}$ in the top chamber to $7 \mathrm{ml}$ in the bottom chamber. Due to the sigmoidal shape of the D/R curve, survival rates $<15 \%$ and $>85 \%$ were not used in calculation of drug concentration ( $\%$ penetration). For this reason, the accessible concentration range was 10-20 $\mu \mathrm{M}$ (DLD-1) and 0.5-1 $\mu \mathrm{M}$ (HT-29) for PTX, and 100-400 $\mu \mathrm{M}$ (DLD-1) and 50-400 $\mu \mathrm{M}$ (HT-29) for 5-FU.

A significant difference in MCL penetration was observed between PTX and 5-FU. Anti-proliferative activity of conditioned media containing PTX decreased significantly after MCL penetration; however, no changes were observed in the case of 5-FU. The \% penetration of PTX was estimated as $24-40 \%$, and $100 \%$ for 5-FU. Full penetration of 5-FU may not represent actual passage of the parent drug since metabolic activation of 5-FU could have occurred. However, because no increase in activity was observed in either of the MCLs, the possibility of metabolic activation should be eliminated. Full penetration of 5-FU shown in our study is also consistent with the results of previous studies (20-22).

PTX showed slow penetration compared to mannitol, which is known to diffuse through a paracellular pathway (Fig. 4). In contrast to hydrophilic mannitol, hydrophobic PTX may diffuse, at least in part, through a transcellular pathway in MCL. Despite the difference in loading concentrations tested between DLD-1 and HT-29 MCLs, dose-dependency was shown for PTX in both MCLs, i.e., $26 \%$ and $40 \%$ at $5 \mu \mathrm{M}$ and $20 \mu \mathrm{M}$ in DLD-1, and $24 \%$ and $38 \%$ at $0.5 \mu \mathrm{M}$ and $1 \mu \mathrm{M}$ in HT-29, respectively (Fig. 3). This concentration dependency, as well as cell line dependency, was confirmed when the penetration profile was obtained using radio-labelled drugs over a period of $96 \mathrm{~h}$ (Fig. 4). Cell line-dependency can be attributed to differences in packing density, as reported by Tannock et al (16). H\&E sections of DLD-1 MCL showed less compactness, compared to that of HT-29, which was not consistent with penetration data, e.g., \% penetration was greater in more compact HT-29 MCL. Since morphology shown on 
H\&E sections may not represent the culture structure due to disorganization and shrinkage induced during paraffin block processing procedures, evaluation of the compactness of MCL architecture using electron microscopic sections may be necessary for determination of whether the difference in penetration rate between DLD-1 and HT-29 MCLs is related to compactness or other reasons, including drug sensitivity.

Penetration of PTX was concentration- and time-dependent, i.e., low penetration rate at lower concentration, and \% penetration increased until 72 or $96 \mathrm{~h}$ (Fig. 4B). Based on this data, it can be speculated that tissue penetration of PTX after i.v. administration in vivo should be dependent on plasma concentration and elapsed time. The penetration rate at $1 \mu \mathrm{M}$ after $24 \mathrm{~h}$ was greater than that of $10 \mu \mathrm{M}$ after $3 \mathrm{~h}$ (at the exposure level of 24-30 $\mu \mathrm{M} \cdot \mathrm{h}$ in HT-29 MCL), which suggests that longer infusion may be more advantageous in enhancement of drug penetration into tumor tissue. PTX is usually given as a 3 -h or $24-\mathrm{h}$ infusion at a dose of 175 or $135 \mathrm{mg} / \mathrm{m}^{2}$, respectively $(17,23)$, and 24 infusions can be more beneficial at the cost of dose reduction, which warrants further investigation. When the plasma concentration drops at the end of i.v. infusion, tissue penetration should also show a significant decrease, resulting in decreased drug concentration in tumors. In this respect, effective drug concentration in tumor tissue and the sensitivity of cancer cells located remotely from blood vessels should be considered simultaneously in order to achieve effective cancer cell killing in tumor masses.

We assessed the effect of sequential treatment with combination of PTX and 5-FU. Anti-proliferative activity of combination treatment increased in DLD-1 MCL (Fig. 5A). However, no difference was shown between sequential and sum of a single treatment $(\mathrm{P}>0.05)$ or between the order of sequential treatment, suggesting a combination effect, but not pharmacokinetic interaction by sequential treatment of PTX and 5-FU. The weak synergistic effect between PTX and 5-FU shown in DLD-1 MCL may be associated with depressed DPD expression induced by PTX, as previously reported (24); nonetheless, this effect was not obvious in HT-29 MCL, where a 20 -fold lower PTX concentration (10 $\mu \mathrm{M}$ vs. $0.5 \mu \mathrm{M})$ was used.

Chemoresistance of solid tumors has been attributed to pharmacokinetic as well as other microenvironmental factors $(2,3,25)$. Distribution of many anticancer drugs within tumors was shown to be poor and heterogeneous. The tumor microenvironment is characterized by disorganized vasculature, irregular blood flow rate, increased interstitial fluid pressure (IFP), hypoxic regions, and abundant extracellular matrix (ECM). Because of these environmental conditions, only a portion of the target tumor cell population (near vessels) is exposed to a potentially lethal concentration of the cytotoxic agents. For improved penetration and distribution of anticancer agents into tumors, it is important to modify or exploit the microenvironment of tumors (3). Many studies using various strategies have been aimed at improvement of the penetration/distribution and effectiveness of anti-cancer drugs. Bevacizumab has been suggested as an agent that can improve tumor perfusion for enhancement of drug penetration (26). Hyaluronidase disintegrating hyaluronic acid has been shown to increase penetration of chemotherapy agents (27).
Raising the $\mathrm{pH}$ in endomes resulted in decreased sequestration of doxorubicin in cells, thereby improving penetration into tumor tissue and increasing cellular toxicity (28).

In the present study, using the $\mathrm{D} / \mathrm{R}$ curve of the drug, we demonstrated the feasibility of an in vitro MCL model for evaluation of drug penetration. Using our model, we demonstrated that tissue penetration of PTX was poor and varied up to 3-fold in a cell line- and concentration-dependent manner. Since no analytical method, such as HPLC, was utilized, our model can be useful in early stage screening of anticancer agents for their potential for tissue penetration. Although we did not observe pharmacokinetic interaction (effect on the penetration rate), this model can also be used for evaluation of phamacokinetic interaction between two anti-cancer agents, especially using PTX or irinotecan, which have been shown to enhance tumor penetration of other drugs.

\section{Acknowledgements}

This study was supported by Mid-career Researcher Program through NRF grant funded by the MEST (No. 2009-0086195) and the Ministry of Knowledge Economy (MKE) and Korea Industrial Technology Foundation (KOTEF) through the Human Resource Training Project for Strategic Technology.

\section{References}

1. Desoize B and Jardillier J: Multicellular resistance: a paradigm for clinical resistance? Crit Rev Oncol Hematol 36: 193-207, 2000.

2. Minchinton AI and Tannock IF: Drug penetration in solid tumours. Nat Rev Cancer 6: 583-589, 2006.

3. Trédan O, Galmarini CM, Patel K and Tannock IF: Drug resistance and the solid tumor microenvironment. J Natl Cancer Inst 99: 1441-1454, 2007.

4. Cowan DS, Hicks KO and Wilson WR: Multicellular membranes as an in vitro model for extravascular diffusion in tumours. Br J Cancer 27: S28-S31, 1996.

5. Tannock IF, Lee CM, Tunggal JK, Cowan DS and Egorin MJ: Limited penetration of anticancer drugs through tumor tissue. Clin Cancer Res 8: 878-884, 2002.

6. Primeau AJ, Rendon A, Hedley D, Lilge L and Tannock IF: The distribution of the anticancer drug Doxorubicin in relation to blood vessels in solid tumors. Clin Cancer Res 11: 8782-8788, 2005.

7. Kuh HJ, Jang SH, Wientjes MG, Weaver JR and Au JL: Determinants of paclitaxel penetration and accumulation in human solid tumor. J Pharmacol Exp Ther 290: 871-880, 1999.

8. Sugahara KN, Teesalu T, Karmali PP, Kotamraju VR, Agemy L, Girard OM, Hanahan D, Mattrey RF and Ruoslahti E: Tissuepenetrating delivery of compounds and nanoparticles into tumors. Cancer Cell 16: 510-520, 2009.

9. Sugahara KN, Teesalu T, Karmali PP, Kotamraju VR, Agemy L, Greenwald DR and Ruoslahti E: Coadministration of a tumorpenetrating peptide enhances the efficacy of cancer drugs. Science 328: 1031-1035, 2010.

10. Hicks KO, Ohms SJ, van Zijl PL, Denny WA, Hunter PJ and Wilson WR: An experimental and mathematical model for the extravascular transport of a DNA intercalator in tumours. Br J Cancer 76: 894-903, 1997.

11. Wilson WR and Hicks KO: Measurement of extravascular drug diffusion in multicellular layers. Br J Cancer 79: 1623-1626, 1999.

12. Phillips RM, Loadman PM and Cronin BP: Evaluation of a novel in vitro assay for assessing drug penetration into avascular regions of tumours. Br J Cancer 77: 2112-2119, 1998.

13. Tunggal JK, Cowan DS, Shaikh $\mathrm{H}$ and Tannock IF: Penetration of anticancer drugs through solid tissue: a factor that limits the effectiveness of chemotherapy for solid tumors. Clin Cancer Res 5: 1583-1586, 1999. 
14. Tunggal JK, Melo T, Ballinger JR and Tannock IF: The influence of expression of P-glycoprotein on the penetration of anticancer drugs through multicellular layers. Int J Cancer 86: 101-107, 2000 .

15. Cowan DS and Tannock IF: Factors that influence the penetration of methotrexate through solid tissue. Int J Cancer 91: 120-125, 2001.

16. Grantab R, Sivananthan S and Tannock IF: The penetration of anticancer drugs through tumor tissue as a function of cellular adhesion and packing density of tumor cells. Cancer Res 66: 1033-1039, 2006.

17. Kang GH, Kim GS, Lee HR, Yuh YJ and Kim SR: A phase II trial of paclitaxel, 5-fluorouracil (5-FU) and cisplatin in patients with metastatic or recurrent gastric cancer. Cancer Res Treat 40: 106-110, 2008.

18. Lu D, Wientjes MG, Lu Z and Au JL: Tumor priming enhances delivery and efficacy of nanomedicines. J Pharmacol Exp Ther 322: 80-88, 2007.

19. Baker JH, Lam J, Kyle AH, Sy J, Oliver T, Co SJ, Dragowska WH, Ramsay E, Anantha M, Ruth TJ, Adam MJ, Yung A, Kozlowski P, Minchinton AI, Ng SS, Bally MB and Yapp DT: Irinophore C, a novel nanoformulation of irinotecan, alters tumor vascular function and enhances the distribution of 5-fluorouracil and doxorubicin. Clin Cancer Res 14: 7260-7271, 2008.

20. Erlichman $\mathrm{C}$ and $\mathrm{Wu} \mathrm{A}$ : Effects of 5-fluorouracil and leucovorin in spheroids: a model for solid tumours. Anticancer Res 11: 671-675, 1991.

21. Lowthers EL, Richard CL and Blay J: Differential sensitivity to short-chain ceramide analogues of human intestinal carcinoma cells grown in tumor spheroids versus monolayer culture. In Vitro Cell Dev Biol Anim 39: 340-342, 2003.
22. Nederman $\mathrm{T}$ and Carlsson J: Penetration and binding of vinblastine and 5-fluorouracil in cellular spheroids. Cancer Chemother Pharmacol 13: 131-135, 1984.

23. Dombernowsky P, Gehl J, Boesgaard M, Paaske T and Jensen BV: Doxorubicin and paclitaxel, a highly active combination in the treatment of metastatic breast cancer. Semin Oncol 23: 23-27, 1996.

24. Miyazaki K, Shibahara T, Sato D, Uchida K, Suzuki H, Matsui H, Yanaka A, Nakahara A and Matsuzaki Y: Influence of chemotherapeutic agents and cytokines on the expression of 5-fluorouracil-associated enzymes in human colon cancer cell lines. J Gastroenterol 41: 140-150, 2006.

25. Oh J-M, Ryu Y-K, Lim J-S and Moon E-Y: Hypoxia induces paclitaxel-resistance through ROS production. Biomol Ther 18: 145-151, 2010.

26. Hurwitz H, Fehrenbacher L, Novotny W, Cartwright T, Hainsworth J, Heim W, Berlin J, Baron A, Griffing S, Holmgren E, Ferrara N, Fyfe G, Rogers B, Ross R and Kabbinavar F: Bevacizumab plus irinotecan, fluorouracil, and leucovorin for metastatic colorectal cancer. N Engl J Med 350: 2335-2342, 2004.

27. St Croix B, Man S and Kerbel RS: Reversal of intrinsic and acquired forms of drug resistance by hyaluronidase treatment of solid tumors. Cancer Lett 131: 35-44, 1998.

28. Lee CM and Tannock IF: Inhibition of endosomal sequestration of basic anticancer drugs: influence on cytotoxicity and tissue penetration. Br J Cancer 94: 863-869, 2006. 